\title{
Dualismo/antidualismo: dos tipos de relacionalidad en la teoría sociológica con- temporánea
}

\author{
Sebastián Raza*
}

\section{RESUMEN}

La distinción holismo/individualismo ha mostrado ser insuficiente para pensar la diversidad de nuevas posiciones en relación al debate acción/ estructura. La distinción dualismo/antidualismo aparece como una alternativa viable para reemplazar a la distinción holismo/individualismo (Archer, 1995; Decoteau, 2015; Piiroinen, 2014). Ambas posturas, dualismo y antidualismo, pueden ser pensadas en el marco de la idea de un "giro" relacional en la sociología (Prandini, 2015). Las teorías pertenecientes a dicho giro comparten la intención de superar las deficiencias y los sesgos inherentes a las posturas individualistas y holistas, e integrar en marcos teóricos más complejos tanto el análisis de la acción como el de la estructura. Sin embargo, el llamado "giro" relacional en la sociología incluye teorías sumamente divergentes. En este sentido, la distinción dualismo/antidualismo denota una de las diferencias fundamentales de estas teorías, a saber: considerar que acción y estructura constituyen una unidad indisoluble y que, por tanto, entre ambos hay una suerte de "complicidad ontológica" (Bourdieu, 1981); o pensar a ambos términos como autónomos pero interrelacionados y que, por tanto, lo que en realidad se observa es un "hiato ontológico" (Archer, 1995). El objetivo de este artículo es presentar el tipo de relacionalidad que se deriva de ambas bajo la etiqueta de relacionalidad estructural (antidualismo) y relacionalidad contingente (dualismo).

PALABRAS CLAVES: dualismo, antidualismo, acción, estructura, teoría sociológica, giro relacional, relacionalidad.

\section{ABSTRACT}

The distinction between holism and individualism has proven to be insufficient to understand the diversity of new positions related to the agency/structure debate. As a consequence, in the last years, the distinction between dualism and antidualism has appeared to improve these limitations

\footnotetext{
* Sebastián Raza (Licenciado en Sociología, Pontificia Universidad Católica del Ecuador). Este artículo se desarrolló en el marco de su investigación para titularse en la Pontificia Universidad Católica del Ecuador, Quito. Actualmente cursa estudios de Maestría en la Universidad de Warwick, Reino Unido. Agradezco al profesor Aldo Mascareño sus observaciones y comentarios críticos que fueron una pieza fundamental para el desarrollo y el planteamiento de las cuestiones centrales presentadas en este artículo.

囚: sebastianrazam@gmail.com

Artículo disponible en: www.revistatheorein.com
} 
and deficiencies (Archer, 1995; Decoteau, 2015; Piiroinen, 2014). Both dualism and antidualism can be related to the idea of a relational "turn" in contemporary social theory (Prandini, 2015). Theories which are representative of this turn share the intention of overcoming the failures of both holism and individualism, and of integrating the analysis of agency and structure in more complex theories. However, the so-called relational "turn" includes a wide range of differing theories. Thus, the distinction dualism/antidualism points out one of the most fundamental differences: that agency and structure constitute a synthetic and indissoluble unit and, therefore, there is an "ontological complicity" between them (Bourdieu, 1981); or to think of both as autonomous but interrelated dimensions with causal powers on their own and, therefore, what is actually observed is an "ontological hiatus" (Archer, 1995). A specific form of conceiving relationality can be derived from each position. The aim of this article is to present both perspectives under the label of structural relationality (antidualism) and contingent relationality (dualism).

Keywords: dualism, antidualism, agency, structure, sociological theory, relational turn, relationality.

$\mathrm{E}^{1}$

1 debate acción/estructura ha sido sin duda uno de los ejes fundamentales del desarrollo de la teoría social contemporánea. La centralidad del debate se deriva del hecho que en él se expresan las posiciones ontológicas básicas que subyacen a toda explicación de los fenómenos sociales. Por un lado, quienes apuestan por centrarse en la acción conciben a la sociedad como el efecto de múltiples acciones individuales entrelazadas. Por el otro lado, quienes se enfocan en la estructura conciben a esta como un fenómeno con poderes causales propios y al individuo como un mero soporte de lo que ocurre a nivel estructural.

Aunque los clásicos de la sociología no hayan pensado términos del debate, es innegable que en su obra se pueden identificar las dos posturas básicas que definieron el desarrollo ulterior de la sociología: holismo e individualismo. En este sentido, Bendix (1971) afirma que la oposición entre Durkheim y Weber debe ser entendida como la fundación de dos 
tradiciones sociológicas opuestas: "ciencia de la acción” y "ciencia de los hechos sociales". En sus palabras,

la sociología de Weber afirma que 'no existen personalidades colectivas capaces de actuar'. En oposición a esta postura, Durkheim enuncia: 'cuando el individuo ha sido eliminado, lo único que queda es la sociedad. Debemos entonces buscar la explicación de la vida social en la naturaleza de la sociedad en sí misma'. Así, Weber siempre duda sobre si se debe conceder a las acciones o ideas un carácter colectivo, mientras que Durkheim lo hace libremente (Bendix, 1971: 291)

Por tanto, Durkheim, al reconocer poderes causales únicamente a los hechos sociales, considera que "todas las veces que se explique directamente un fenómeno social por un fenómeno psíquico [individual] se puede tener la seguridad de que la explicación es falsa” (Durkheim, 2009: 163). El pensador francés no duda en afirmar que los hechos sociales son de una naturaleza distinta, poseen características propias y son la base de la sociedad. Por tal motivo, en el pensamiento durkheimiano, los individuos "no son más que la materia indeterminada que el factor social determina y transforma" (Durkheim, 2009: 165). ${ }^{1}$

Por otro lado, Weber, al negar poderes causales al ámbito supraindividual y considerar que el individuo es el único elemento en la sociedad capaz generar efectos causales efectivos, afirma que "la sociología solo puede proceder de las acciones de uno o más individuos separados y, por tanto, debe adoptar métodos estrictamente individualistas" (citado en Mommsen, 1965: 44). ${ }^{2}$ Por tanto, para el sociológo alemán, el

\footnotetext{
${ }^{1}$ Se podría incluir a Marx en esta tradición, pues aunque con un enfoque epistemológico distinto, él comparte estos presupuestos ontológicos con Durkheim al afirmar que "no es la conciencia de los hombres lo que determina su ser sino, por el contrario, su ser social es lo que determina su conciencia" (Marx, 2012: 1976). Ello tiene claras consecuencias en el pensamiento marxista. Una de ellas es la concepción de las personas exclusivamente como agentes de clase y, al fin de acabo, resortes estructurales. Por ello, Marx afirma que "solo se trata de personas en la medida en que son la personificación de categorías económicas, portadores de determinadas relaciones e intereses de clase" (Marx, 1977: 8).

${ }^{2}$ En este punto, no sobra explicar que, en los pensadores alemanes, el término método no se refiere
} 
Estado, el feudalismo, la burocracia y cualquier otro concepto que haga referencia a fenómenos supraindividuales "designan, para la sociología, en general, categorías que se refieren a modos determinados de actuar humano en sociedad, y por lo tanto su tarea consiste en reducirlos a un actuar 'comprensible', lo cual significa, sin excepción al actuar de los hombres participantes" (Weber, 2006: 188). Es importante reconocer que todo "actuar humano en sociedad" (Gessellschaftshandeln) implica que los individuos reconozcan validez a algún ordenamiento y que guíen su acción a partir de este reconocimiento (Weber, 2006). En palabras de Weber, los ordenamientos unicamente son

representaciones de algo que en parte existe y en parte se presenta como un deber ser en la mente de hombres concretos [...] la acción de los cuales orientan realmente; y también debe tomar nota de que esas representaciones, en cuanto tales, poseen una poderosa, a menudo dominante, significación causal en el desarrollo de la conducta humana concreta" (Weber, 2014: 103).

Así, toda asociación o concepto supraindividual - como Estado solo tiene sentido por "su referencia a la acción humana, ya como medio, ya como fin imaginado por el actor o actores y que orienta su acción" (Weber, 2014: 133). De la misma manera, todo "actuar humano en sociedad"

únicamente a las técnicas de recolección de información. Esta noción ya fue expresada por Parsons cuando afirmaba que "debe ser remarcado que la palabra método se refiere en la sociología norteamericana a técnicas de investigación, mientras que en Alemania se refiere en cambio a lo que se ha denominado filosofía de la ciencia, es decir, que involucra los fundamentos de su marco de referencia y sus esquemas conceptuales" (Parsons, 1979: 5). Por consiguiente, la idea de método individualista en Weber no se reduce únicamente al individualismo metodológico, sino a todo un fundamento operativo ontológico y epistemológico que involucra al individualismo ontológico. De esta forma, el aserto de Gil Villegas según la cual " aunque él [Weber] puede ser visto como un individualista metodológico, jamás fue un individualista ontológico" (Gil Villegas, 2014: 82) no debe ser aceptada sin discusión. Es claro que esta tesis puede ser muy debatida, pero si se toman en cuenta conexiones entre el nivel metodológico, epistemológico y ontológico (Mascareño, 2008) estamos obligados a considerar que no se puede ser individualista metodológico sin dejar de ser individualista ontológico y sin caer en una teoría incoherente e irrealista, una postura que pensador tan riguroso como Max Weber nunca pudo haber aceptado. 
requiere de "acción en sociedad" (Vergesselschaftung), es decir de la posibilidad de que sucedan un cojunto de acciones mutuamente referidas a partir de aquellas representaciones (Weber, 2006). Por tanto, las entidades o fenómenos supraindividual, para Weber, solo pueden conceptualizarse en términos individuales "materiales" - como entrelazamientos de acciones específicas - o en términos individuales "ideales" - como representaciones que guían la acción de los individuos.

Varias corrientes sociológicas posteriores se han situado en el polo individualista - interaccionismo simbólico, fenomenología, teoría de la acción racional, entre otros-o en el polo holista-estructural funcionalismo, marxismo estructural, teoría de sistemas, entre otros-. No obstante, desde mediados del siglo XX, la sociología se percató de las ventajas y sesgos inherentes a ambas posturas y la obra de varios pensadores importantes tuvo como objetivo integrar el estudio de la acción y de la estructura en marcos teóricos más abarcativos y complejos. Entre ellos destaca la obra de Pierre Bourdieu con la distinción habitus/campo (2013a), la teoría de la estructuración y la dualidad de la estructura de Anthony Giddens (1979) y el modelo morfogenético propuesto por Margaret Archer (1995). Aunque estos distintos desarrollos teóricos tengan como punto común la integración de la acción y la estructura, sería un grave error considerar que puedan considerarse homogéneos. ${ }^{3}$

Uno de los rótulos bajo los cuales se ha pretendido comprender estos intentos es el de sociología relacional. Se los ha comprendido bajo este rótulo, puesto que afirman que el individuo solo puede ser considerado a la luz de las relaciones de las que forma parte y que lo conforman.

\footnotetext{
${ }^{3}$ Algunos autores han pretendido considerar que todos estos desarrollos pueden ser entendidos indistintamente como metodologías relacionistas (Ritzer \& Gindoff, 1992; Ritzer, 1993). Sin embargo, las teorías que se pretenden entender bajo este rótulo poseen diferencias irreconciliables que necesitan ser tomadas en cuenta para estudiar de forma más rigurosa la teoría social contemporánea.
} 
Lo relacional se plantea como el producto del vínculo entre acciones relexivas e intencionales con interdependencias sistémicas y estructurales, de manera que las relaciones se muestran como un fenómeno producido por procesos sociales complejos. No obstante, tal como afirma Dépelteau (2013), las distintas teorías que forman parte de la sociología relacional no tienen un concenso a nivel ontológico. Como consecuencia, la forma en que se conciben las partes integrantes de la acción humana y el rol de la estructura en su conformación varía sustancialmente. Por tanto, estas teorías "relacionales" remiten a formas distintas y divergentes de conceptualizar lo relacional en base a presupuestos ontológicos ligados a la forma en que se concibe al ser humano y a la sociedad.

Así, tal como afirma Prandini (2015), más que hablar de un paradigma definido de sociología "relacional", se debe entender a estos intentos teóricos como parte un "giro" relacional en la sociología que tiene como característica compartida la crítica a las corrientes holistas e individualistas, y la superación de sus sesgos a partir de conceptos e ideas que hacen referencia a que la sociedad está compuesta de relaciones sociales y otorgan a ellas un papel central. ${ }^{4} \mathrm{~A}$ decir del italiano, dicho "giro" es importante "porque fuerza a la sociología a especificar con precisión la ontología de la sociedad y las relaciones sociales, y a descubrir nuevos métodos y técnicas de investigación apropiadas para su estudio" (Prandini,

\footnotetext{
${ }^{4}$ Debido a las distintas tradiciones intelectuales en las que se enmarcan los tres autores, cada uno se alejó respectivamente de las corrientes individualistas y holistas predominantes en sus círculos intelectuales. Bourdieu construye su teoría en confrontación con la corriente que él denomina subjetivismo, en la que incluye el existencialismo sartreano y la teoría de la acción racional, y con la que denomina objetivismo, en el que incluye el marxismo estructural de Althusser y el estructuralismo de Saussere y Levi-Strauss (Bourdieu, 2013a). Por su parte, Giddens busca alejarse de los sesgos del "imperio del objeto", que se identifica con el funcionalismo en general, y de los sesgos del "imperio del sujeto", que se identifica con la sociología interpretativa de corte weberiano (Giddens, 1979; 1995). Por último, Archer critica la tradición colectivista e individualista inglesa (Archer, 1995). A pesar de que los autores critican distintas tradiciones, se puede afirmar que estas son equivalentes a nivel de presupuestos ontológicos y pueden ser agrupadas bajo el rotulo de individualismo y holismo respectivamente.
} 
2015: 13). Sin embargo, no es posible, tal como lo hace Dépelteu (2013), pensar la ontología del "giro" relacional en base a la distinción holismo/ individualismo y dejar como categoría residual a las teorías que han pretendido unir acción y estructura bajo la etiqueta de "codeterministas". 5

Por tanto, para mejorar la comprensión del "giro" relacional es necesario crear códigos binarios que ayuden a reducir complejidad al tiempo que permitan observar las distintas teorías que forman parte de lo que erróneamente Dépelteu llama codeterminismo en perspectiva para diferenciarlas unas de otras. Este artículo pretende presentar la distinción dualismo/antidualismo como uno de los ejes fundamentales para la comprensión de dicho "giro" y el desarrollo actual de la teoría sociológica en la medida en que esta distinción apunta a distintas formas de conceptualizar lo relacional, es decir, a distintas formas de relacionalidad que no pueden ser compatibles sin un esfuerzo teórico anterior. ${ }^{6}$

Mostrar el panorama total de la teoría sociológica contemporánea que se enmarca en este "giro" relacional y que puede ser pensada a partir de la distinción dualismo/antidualismo excede los límites de este artículo, pues incluye la obra de Tilly, Emirbayer, Donati, Archer, Bourdieu, Giddens, Elías, Habermas, Luhmann, Latour, entre otros. Sin embargo, al rastrear las raices de la distinción y estudiar sus precursores se puede ensayar la formación de un marco metateórico general tanto de dualismo como de

\footnotetext{
${ }^{5}$ Lo que hace Dépelteu es afirmar que, a fin de cuentas, Bourdieu y Archer comparten el codeterminismo y lo único que les diferencia son los niveles de importancia que le dan a las nociones de acción y estructura. En sus palabras, "se puede reconocer fácilmente a una teoría codeterminista porque, analíticamente o no, con más énfasis en la agencia, reflexividad, estructuras o hábitos, estas teorías están basadas en la idea de que la historia es el efecto de la interacción entre las propiedades de la estructura social y la agencia" (2013: 172).

${ }^{6}$ En el debate sociológico ecuatoriano, no se ha considerado más propuestas de integración de la acción y la estructura que la de Bourdieu, la de Giddens y, de forma superficial, la de Habermas. En este sentido, exponer la propuesta dualista por excelencia de Margaret Archer no sólo implica introducir un nuevo punto de vista en cuanto al debate, sino también presentar el eje dualismo/ antidualismo como un punto de inflexión en la forma en que se han pensado las soluciones al debate acción/estructura.
} 
antidualismo que sea lo suficientemente abstracto como para abarcar más teorías y lo suficientemente concreto para diferenciarse claramente una postura de la otra al tiempo que se evidencia al tipo de relacionalidad que denota cada una.

El par binario dualismo/antidualismo se deriva de la observación que realiza Archer al afirmar que "lo que no desapareció, a pesar de la prematura celebración de un nuevo consenso, fue la necesidad de elegir. Los nuevos términos a partir de los cuales se reconceptualizó 'agencia y estructura' estuvieron de nuevo representados por dos puntos de vista" (Archer, 1995: 60). Los términos que la profesora de Warwick utiliza para designar estas dos posturas son "elisionismo" y "emergentismo". La diferencia entre ambos consisteen que los primeros piensan acción y estructura como elementos indisolubles en un proceso de mutua constitución, mientras que los segundos consideran que, en realidad, ambos son fenómenos autónomos pero poseen capacidad de influencia causal mutua. ${ }^{7}$ Como se evidenciará a lo largo de este artículo, esta diferencia fundamental tiene grandes consecuencias a la hora de pensar lo relacional desde estos programas teóricos específicos, de forma que surgen dos tipos de relacionalidad.

Sin embargo, aunque en su contenido sean utiles, los términos acuñados por Archer deben ser reemplazados puesto que el término 'elisionismo' conlleva la crítica que Archer realiza a las propuestas antidualistas, en las que incluye a Bourdieu y Giddens, y el término ‘emergentismo’ hace referencia simplemente al enfoque morfogénetico que no es más que una de las opciones dualistas. Para superar los términos propuestos por Archer y volverlos más generales, este artículo revisará en el primer apartado a las propuestas de Bourdieu y Giddens, a fin de

\footnotetext{
${ }^{7}$ Donati también realiza esta distinción con otros términos: teorías relacionales y teorías relacionistas. Y utiliza el segundo término para referirse a las que en este artículo son consideradas antidualistas, pues buscan explicar la relación entremezclando las acciones individuales y las estructuras sociales en lugar de explicarla como un fenómeno relativamente autónomo que surge de los poderes causales de ambas pero que no puede ser reducida a ellas (Donati, 2015).
} 
crear un marco metateórico antidualista y de esbozar la concepción de relacionalidad que de este se deriva; y, en el segundo apartado, la propuesta de Archer con miras a crear un marco metateórico dualista y la forma en que se concibe la relacionalidad desde este punto de vista. En el último apartado, se explicitarán las diferencias generales encontradas en relación a la constitución de la mente humana y lo relacional, y se expondrán algunos desarrollos actuales de la teoría sociológica que pueden ser entendidos desde la distinción propuesta.

\section{Antidualismo: mente socialmente "limitada" y relacionalidad estructural}

Las propuestas antidualistas tienen como punto de encuentro la intención de evidenciar la inseparabilidad de acción y estructura a partir de un asunto central en el que se dan procesos de interiorización y de exteriorización constantes. Las teorías antidualistas por excelencia son la teoría de la estructuración de Giddens y la teoría del habitus de Bourdieu. Las similitudes entre ambas se derivan de premisas ontológicas básicas que conciernen a la forma en que se concibe al ser humano como un ser exclusivamente social. Situar a ambas obras bajo un mismo rótulo no es algo nuevo. Por el contrario, algunos autores encuentran similitudes entre ellos y los clasifican como una corriente específica (Ritzer, 1993; ElderVass, 2010; Emirbayer \& Mische, 1998). El punto de encuentro de ambos autores es la centralidad del concepto práctica en su arquitectura teórica, donde estructura y acción covarían. Por estos motivos Emirbayer y Mische (1998) afirman que es apropiado considerar a estos dos autores como los grandes teóricos de las prácticas sociales.

A grandes rasgos, podemos definir la práctica como el proceso en el cual estructura y acción convergen, de manera que se demuestra su 
inseparabilidad y mutua constitución. Giddens es explícito cuando afirma que "el dominio primario de las ciencias sociales, para la teoría de la estructuración, no es ni la vivencia del actor individual ni la existencia de alguna forma de totalidad societaria, sino prácticas sociales ordenadas en un espacio y tiempo" (Giddens, 1995: 40). Bourdieu, a su vez, afirma que "es necesario retornar a la práctica, ámbito de la dialéctica del opus operatum y del modus operandi [...] de la estructura y de los habitus" (Bourdieu, 2013a: 85-6). La noción de práctica es utilizada por ambos autores para introducir la acción de los sujetos en las estructuras como parte integrante de ellas, y viceversa. En otras palabras, la práctica hace evidente que no existe estructura sin acción, ni acción sin estructura; o, en otras palabras, que toda acción implica el uso recursivo de elementos estructurales y que este uso es necesario para la existencia de la estructura.

Al ser la práctica el proceso en el que confluyen ambas entidades, se constituye esta como la unidad en la que las diferencias entre las propiedades individuo y las propiedades de la sociedad convergen. Es decir, no se pueden estudiar las estructuras sin tomar en cuenta la acción, así como tampoco se puede estudiar la acción sin tomar en cuenta la estructura; pues, en su encuentro, ambos se codeterminan. En términos de Bourdieu, para analizar un campo como un conjunto de relaciones objetivas hay que remitirse al habitus de los agentes que lo conforman, y para analizar un habitus es necesario remitirse a los campos y relaciones objetivas en los que estos fueron moldeados en un espacio y tiempo definidos. Evidentemente, esta es una concepción que no se opone diametralmente ni al holismo ni al individualismo, sino que busca hacer que estos converjan. Este rasgo compartido es el que hace que estos autores se opongan al dualismo y lo califiquen de falso dualismo (Bourdieu) o lo reconceptualicen como dualidad (Giddens). 
En este sentido, Bourdieu afirma que asegurar la existencia objetiva de las estructuras sociales sin tomar en cuenta el rol de la acción individual, tal como hace el holismo, "al separar el sentido objetivo que ella trae a la luz de los agentes que lo hacen funcionar $\mathrm{y}$, de esa manera, de las condiciones objetivas y de los fines prácticos con referencia a los cuales se define su práctica, ella impide comprender cómo se cumplen esas funciones" (Bourdieu, 2013a: 153). De igual manera, Giddens afirma que el error de Durkheim consiste en "considerar el constreñimiento social como si fuera similar al constreñimiento físico, y es un error también creer que lo social e institucional solamente son fuente de constreñimiento" (Giddens, 1979: 51). Así, los antidualistas reconceptualizan la estructura como fuente de recursos y posibilidades objetivas. Contra el determinismo holista, la estructura, más que determinar y prohibir ciertas formas de acción, brinda posibilidades para la acción humana que permiten que esta sea de uno u otro modo. Giddens afirma que este hecho expresa el "carácter fundamentalmente recursivo de las prácticas sociales y expresa la mutua dependencia de la estructura y la acción" (Giddens, 1979: 69).

Por su parte, la reconceptualización de Bourdieu debe entenderse desde el par conceptual habitus/campo. Para el pensador francés, el campo se entiende como un espacio estructurado que permite y configura la acción del habitus y que solo existe en relación a este. En oposición a Durkheim, Bourdieu propone que los hechos sociales deben ser tratados como cosas externas al sujeto, pero sin olvidar que estos también se muestran como objetos de reflexión y asimilación del habitus de los agentes. En este sentido, Bourdieu afirma, en relación a los campos, que

son objetos de conocimiento (aunque se trate de un desconocimiento) en la objetividad misma de lo social. Y [...] debe introducir en su definición completa del objeto a las representaciones iniciales del objeto, que primero ha debido destruir para conquistar la definición “objetiva” (Bourdieu, 2013a:217). 
Sin embargo, es necesario afirmar que el habitus está estructurado por las condiciones objetivas en las que el agente se encuentra, es decir, por su ubicación en un campo de relaciones objetivas y de reglas de sentido. De esta forma, la noción de campo de Bourdieu implica la existencia de

relaciones objetivas que existen independientemente de la conciencia o voluntad individual [...] estas posiciones están objetivamente definidas, en su existencia y en las determinaciones que imponen sobre sus ocupantes por su situación presente y potencial en la estructura de distribución de especies del poder cuya posesión ordena el acceso a ventajas específicas (Bourdieu, 2008: 134-5).

Así, la relación entre habitus y campo es indisoluble: el agente asimila la objetividad del campo a partir de esquemas mentales que fueron adquiridos en campos específicos. Como se puede observar en ambos autores existe también una reconceptualización de la capacidad creadora del agente a partir de la noción redefinida de estructura. La acción no puede ser autónoma en estricto sentido, pues está configurada por las estructuras. Según los antidualistas, la autonomía de la agencia no puede ser total, tal como los individualistas reclaman, pues esta se enmarca en microcosmos y contextos sociales específicos que la configuran, la limitan y le brindan potencialidades a su acción. De esta forma, Bourdieu afirma que

si bien es bueno recordar, contra cierta visión mecanicista de la acción, que los agentes sociales, individual, y también colectivamente, construyen la realidad social, es necesario no olvidar [...] que ellos no construyen las categorías que hacen funcionar en esa construcción [...] [estas] resultan de un largo y lento proceso inconsciente de incorporación de las estructuras objetivas (Bourdieu, 2013b: 50).

De esta forma Bourdieu afirma que la práctica actualiza al habitus y al campo en su confrontación. Así pues, el habitus no solo tiene efectos causales sobre el campo, sino que este también configura a aquel en su encuentro. Por tal motivo, se puede afirmar que existe una suerte de 
covariación entre estructuras y acciones. La noción de habitus, dice el francés, busca "hacer hincapié en las capacidades creativas e inventivas del ser humano, pero hacerlo sin recaer en la idea de que este poder deriva de una mente universal o la naturaleza humana [...] sino del agente que actúa" (Bourdieu, 1985:13). En este sentido, Bourdieu afirma que existe normalmente una continuidad entre los habitus y los campos, como producto de los límites que las estructuras imponen a la mente humana. De ahí que el habitus "tiende, con más seguridad que todas las reglas formales y todas las normas explícitas, a garantizar la conformidad de las prácticas" (Bourdieu, 2013a: 88).

Si bien se acepta del individualismo que los individuos tienen la capacidad de interpretar el mundo y otorgarle sentido al mismo tiempo que direccionan su acción racionalmente con arreglo a intereses y valores, la racionalidad así como los intereses y los valores no son concebidos como un fenómeno autónomo en el que cada sujeto decide individualmente y voluntariamente a cuáles demonios rinde su obediencia para, a partir de ello, actuar racionalmente, sino como "interés específico, intereses que son tanto presupuestos como producidos por el funcionamiento de campos históricamente delimitados" (Bourdieu, 2008: 156). Así, la conciencia que reclaman los antidualistas para el individuo no es la autónoma del individualismo, sino una conciencia práctica que, en tanto sirve para la práctica, está íntimamente ligada con la estructura y limitada por ella. Esto quiere decir que se considera que la mente humana tiene una naturaleza social. La relación entre campo (estructura), interés y habitus (acción) se evidencia en que "cada campo convoca y da vida a una forma específica de interés, una illusio específica, bajo la forma de un reconocimiento táctico del valor de los asuntos en juego y el dominio práctico de sus reglas" (Bourdieu, 2008: 156). Así, Bourdieu afirma que las motivaciones surgen de las potencialidades objetivas del presente y de los campos estructuradores 
del habitus, "al contrario del futuro como posibilidad absoluta" (Bourdieu, 2013a: 87). De esta forma, Bourdieu llega a hablar del habitus como portador de una capacidad de invención limitada y de libertad negativa.

De igual manera, Giddens, al introducir la idea de dualidad de la estructura, afirma que los intereses no pueden provenir de los individuos autónomamente. El inglés afirma que "los actores saben mucho sobre las condiciones de y consecuencias de lo que hacen en su vida cotidiana" (Giddens, 1995: 307), pero que las razones que surgen en la conciencia del sujeto, lejos de poseer autonomía absoluta, se encuentran reguladas por el contexto espacio-temporal de la acción, pues a "las actividades humanas sociales que se autroproducen y son recursivas [...] los individuos no les dan nacimiento, [por el contrario] las recrean, pero a su vez en sus actividades cotidianas, crean las condiciones para su producción" (Giddens, 1995: 40). Así, lo que se le atribuye al humano es la capacidad de conocer su presente, el mundo social circundante y aplicar esquemas y recursos que han adquirido del pasado. En conclusión, el humano es tratado única y estrictamente como ser social, pues no puede conocer nada fuera de lo que ha interiorizado de la sociedad, es decir, está moldeado por las estructuras circundantes y su conciencia, aunque autónoma y productora, está conformada únicamente por estructuras que tienen un origen social.

Para no negar por completo la idea de motivación, como algo inherente del ser humano, como una conexión de sentido que realiza el sujeto en cuanto individuo, Giddens afirma que esta "alcanza el dominio directo sobre la acción solo en circunstancias relativamente inusuales, en situaciones que de algún modo quiebran la rutina" (Giddens, 1995: 44). Tal hecho queda evidenciado en la distinción que el pensador inglés realiza entre los distintos tipos de "conciencia práctica" que el agente posee. Esta puede ser "reflexiva", "racional" o "rutinaria". La primera surge en los momentos en que se quiebra la rutina, pero esta no es totalmente autónoma, 
sino que depende de los contextos en los cuales se enmarca la acción y de los esquemas aprendidos en el pasado. La segunda se perfila como el producto de la comprensión teórica del mundo social y las estructuras. Por último, la tercera surge de la acción constante en contextos específicos (Giddens, 1995). Lo interesante, en este proceso de reconceptualización de la acción, es que no se acepta de ninguna manera que esta sea autónoma e independiente, sino que, en sus tres posibilidades, la conciencia siempre está configurada por las estructuras circundantes aunque en algunos casos permita mayores niveles de reflexividad.

Al igual que lo piensa Giddens, Bourdieu afirma que cuando no existe la concordancia entre habitus y campo aparece la capacidad creativa e inventiva del sujeto, pero de forma limitada, pues Bourdieu afirma que, en un proceso de desfase, el habitus solo puede actuar a partir de las estructuras mentales pasadas sin importar que obtenga resultados negativos. A este fenómeno, Bourdieu lo denomina histéresis del habitus y lo define como una situación en la que "las prácticas están objetivamente inadaptadas a las condiciones presentes debido a que se ajustan objetivamente a condiciones caducas" (Bourdieu, 2013a: 101). Evidentemente, al igual que Giddens, el pensador francés niega parcialmente la capacidad creadora del ser humano y solo la reconoce parcialmente en casos límite en los que ha existido un cambio en las estructuras sociales.

Por tanto, para los antidualistas, el individuo de ninguna manera puede ser entendido como un ser autónomo sino como un ser social, o en palabras de Bourdieu, como un ser con sentido práctico, pues "la mente humana está socialmente limitada, socialmente estructurada" (Bourdieu, 2008: 166). De aquí que las estructuras, mas no los individuos, son la fuente de motivaciones, interpretaciones, intereses, etc., que el sujeto en su práctica utiliza recursivamente. Todo fin, interés o esquema de pensamiento es uno que ya está realizado en las estructuras. Así pues, sería un error considerar 
que la reflexividad o la intencionalidad son el producto estratégico del individuo autónomo, pues los "esquemas de pensamiento" y las "reglas" se interiorizan en el actor y guían sus formas de acción subsiguientes aunque estas parezcan producto de una deliberación estratégica.

Tanto la idea de habitus como la de rutina tienen la ventaja de contextualizar la acción humana en estructuras específicas y, al mismo tiempo, de dotar al humano de la capacidad de ejercer algunas propiedades agenciales. Estas se refieren directamente al modo en que las estructuras pasadas influyen dentro del presente, o a cómo las estructuras en las que se formó el habitus influyen en las que este actúa. Al mismo tiempo, sin embargo, estas categorías oscurecen la importancia de que la acción se oriente al futuro, entendido como la capacidad de imaginar posibilidades alternativas, y las formas en las cuales esta motivación futura del agente influye en la contextualización de hábitos pasados en las contingencias de la estructura presente (Emirbayer \& Mische, 1998). De igual manera, esta forma de conceptualizar la acción de los individuos no permite evidenciar que existen acciones más allá de lo que está ahí para ser vivido. Tal hecho conduce a que se le reste importancia a la contingencia de la iniciativa individual.

Lo que la ontología de la práctica social presenta, en conclusión, es una relación ambivalente entre la determinación y la libertad, la acción y la estructura. Esto quiere decir que, en su proceso de reconceptualización, busca evitar pensar la acción y la estructura como dos elementos separados y los conciben como dos fenómenos íntimamente ligados en el proceso de la práctica. En este sentido, Bourdieu considera que la práctica se constituye como el proceso central en el cual los habitus estructuran a los campos y, al mismo tiempo, son estructurados por estos. En otras palabras, el habitus no puede existir sin campos, así como los campos no pueden hacer nada sin la 
mediación del habitus, es decir, acción y estructura son un falso dualismo de la teoría social. En este sentido, Bourdieu afirma que

la teoría de la práctica en cuanto práctica recuerda, contra el materialismo positivista, que los objetos de conocimiento son construidos, y no pasivamente registrados, y, contra el idealismo intelectualista, que el principio de dicha construcción es el sistema de las disposiciones estructuradas y estructurantes que se constituye en la práctica, y que está siempre orientado hacia funciones prácticas (Bourdieu, 2013a: 85).

Esta visión lleva a ambos autores a afirmar que existe una unidad ontológica (Bourdieu la denomina "complicidad ontológica" (Bourdieu, 1981) y Giddens introduce el término dualidad (que parece ser más un concepto ontológico que gnoseológico) entre entidades supraindividuales y entidades individuales. En fin, no se distingue la una de la otra en ninguna de las operaciones que realiza la teoría. No se les otorga autonomía temporal ni analítica. En otros términos, la acción queda, al fin y al cabo, regulada estructuralmente; las motivaciones configuradas estructuralmente; y la relación y el funcionamiento de las estructuras quedan reguladas por la acción. El objetivo consciente de los antidualistas es mostrar que ambas entidades deben pensarse como fenómenos inseparables (como dualidad) y nunca por separado (como dualismo), aun cuando esta tesis parezca llevar a una explicación circular entre acción y estructura. Por ello, Bourdieu afirma que

dado que las disposiciones inculcadas perdurablemente por las posibilidades e imposibilidades, las libertades y las necesidades, las facilidades y los impedimentos que están inscritos en las condiciones objetivas [...] engendran disposiciones objetivamente compatibles con esas condiciones y en cierto modo preadaptadas a sus exigencias, las prácticas más improbables se ven excluidas (Bourdieu, 2013a: 88). 
El antidualismo considera, en contra del individualismo y el holismo, que la relación entre acción y estructura es indisoluble y que ocurre en dos direcciones: condicionamiento y conocimiento (o, en palabras de Bourdieu, construcción cognoscitiva). El condicionamiento implica que las estructuras tienen poder para configurar los elementos que constituyen la acción (motivación, reflexividad, intereses, esquemas de interpretación), mientras que el conocimiento hace referencia al proceso subjetivo que interviene en la interpretación del mundo como objeto de conocimiento que se presenta a los individuos. El proceso de construcción cognoscitiva y significativa, sin embargo, no es, tal como el individualismo lo enunciaba, autónomo y derivado únicamente del individuo, sino que es el producto de las relaciones sociales y las estructuras en las cuales este se desenvuelve. Por ende, el proceso de conocimiento de lo social está regulado por la objetividad misma que se conoce.

La reconceptualización tanto de acción como de estructura en el antidualismo pretende la introducción de la dimensión subjetiva de la representación del agente en la objetividad de las reglas y posiciones de las estructuras, y viceversa, a partir de la configuración de la práctica. Pero esta dimensión subjetiva está configurada por las reglas y posiciones objetivas. En palabras de Giddens, "se necesita una teoría del sujeto que incluya consideraciones sobre las condiciones y consecuencias de su acción, y una interpretación de la estructura como indisoluble de esas condiciones y consecuencias" (Giddens, 1979: 49). Por ello, Giddens define la estructura como medio y fin de la acción (Giddens, 1979), y Bourdieu concibe al campo como un espacio de juego que funciona únicamente cuando los jugadores entran en él y al habitus como un conjunto de reglas y fines ya realizados que no tienen sentido fuera de un campo específico (Bourdieu, 2013a). 
En este sentido, todo marco teórico antidualista debe tener dispositivos teóricos que, mediante la reconceptualización de la acción y la estructura, logren pensar lo social indisolublemente replicado a nivel individual y recuperar el rol de las acciones en la construcción y mantenimiento de las estructuras presentes. Al mismo tiempo, debe reconocer la capacidad estratégica de reflexión de los agentes para movilizar recursos en las distintas estructuras que actúan siempre dentro de marcos de acción configurados por contextos estructurales. Como se ha visto, Bourdieu logra este objetivo mediante la idea de campo, habitus y práctica y Giddens mediante el concepto dualidad, rutina y práctica. Sin embargo, pueden darse otras propuestas antidualistas que utilicen otras categorías para mostrar que la sociedad es el producto de relaciones indisolubles entre acciones y estructuras. En el pensamiento antidualista, ni las entidades supraindividuales ni las individuales son irreductibles. Por el contrario, ambos son coconstitutivas y covarían en el nivel de la práctica, o cualquier otro proceso, que aparece como un proceso temporal unívoco y sincrónico en el cual se activan propiedades causales circulares. En otras palabras, las entidades supraindividuales son reductibles a las individuales y viceversa. Esto hace que la práctica aparezca como una fusión en la que acción y estructura son prácticamente indistinguibles puesto que covarían. Por esta causa, los fenómenos pertenecientes al habitus - motivaciones, intereses, representaciones - no pueden pensarse sin la referencia a un campo específico, así como las posiciones, las reglas de sentido y la situación de un campo no pueden ser definidos si no es en referencia a la acción de sujetos específicos.

El tipo de relacionalidad al que remite un marco teórico antidualista puede ser conceptualizado como relacionalidad estructural en la medida en que logra observar la importancia las estructuras al momento de la configuración de las relaciones sociales. Giddens conceptualiza la relación 
social a nivel de sistema social. De manera que la base de los sistemas sociales consiste en relaciones de interdependencia entre individuos o grupos. Al mismo tiempo, afirma que estos sistemas tienen estructuras (o propiedades estructurales) que deben pensarse como recurso y resultado de las acciones que lo reproducen (dualidad de la estructura). En sus palabras, "estudiar la estructuración de un sistema social es estudiar la forma en que un sistema, mediante la aplicación de reglas generativas y recursos, y en el contexto de resultados no deseados, es producido y reproducido en la interacción" (Giddens, 1979: 66). De esta forma, la relacionalidad se conceptualiza como el producto del uso recursivo de propiedades estructurales que son producidas por sistemas sociales en los que se encuentran relaciones objetivas. En otros términos, la limitación social de la mente humana contribuye a que la relacionalidad en la que se envuelven los agentes no sea otra sino la que ya está estructurada en los sistemas sociales.

De igual forma, al conceptualizar al campo como un espacio de posiciones y relaciones objetivas que generan un habitus de acuerdo a estas condiciones y que será la base de la percepción, valoración y acción de todas las experiencias ulteriores, la relacionalidad que se deriva del marco teórico de Bourdieu no es sino una relacionalidad estructurales en la medida en que asume que las relaciones en las que los sujetos entran son homólogas o equivalentes a las que existen objetivamente en el campo. Aunque Bourdieu conceptualice la relacionalidad en términos de lucha por capitales, la lucha siempre está regulada y estructurada por la objetividad de las relaciones que se enfrentan. En este sentido, como diría Alexander, "para Bourdieu la socialización no transmite valores que se hallen en tensión con la vida que-está-allí-para-ser-vivida; más bien, produce valores que son reflejos inmediatos de las estructuras jerárquicas de la vida material" (Alexander, 2001: 55-6). Así, los antidualistas no conciben relaciones más 
allá de las que ya se encuentran en las estructuras objetivas debido a que conciben la mente humana como mente exclusivamente social.

Las relacionalidad estructural no surge de una subjetividad que enfrenta la objetividad de otras relaciones. Por el contrario, de los postulados antidualistas se deriva que la relacionalidad es el producto de operaciones objetivantes de los sujetos que son configuradas a su vez por la objetividad misma, es decir, por las estructuras existentes que, al fin y al cabo, remiten a un sistema de posiciones y relaciones que está más allá de los individuos. Puesto en otros términos, existen relaciones objetivas de las cuales se derivan esquemas de pensamiento y acción que limitan la mente humana y que los individuos utilizan recursivamente para entrar en o interpretar las relaciones objetivas primeras. Evidentemente, al pensar la relacionalidad de esta forma se corre el riesgo de que se la sobreestructure y se reproduzcan sesgos holistas. Con todo, la noción de relacionalidad estructural permite pensar procesos en los cuales esta se reproduce inconscientemente.

\section{Dualismo: principio de humanidad y relacionalidad contingente}

El trabajo de Margaret S. Archer se ha considerado como el máximo exponente del dualismo (Kemp, 2012; Piiroinen, 2014; Decoteau, 2015). Es importante resaltar que su propuesta teórica se construye a partir de la crítica al antidualismo. En este sentido, la profesora de Warwick afirma que "dado que el habitus de Bourdieu enfatiza en la preadaptación de las personas a las circunstancias, y en la semiconsciente y casi automática naturaleza de sus operaciones, es difícil pensar un concepto menos apropiado para la deliberación consciente de elecciones novedosas" (Archer, 2010: 288-9). De modo similar, en relación a Giddens, Archer critica la forma en que 
sobresocializa al agente humano y presenta una visión confusa acerca de la posibilidades de libertad y reflexión al tiempo que su noción de estructura resulta confusa, pues se reconoce su existencia simplemente en conjunción con la acción humana (Archer, 1982).

De esta manera, la reconceptualización que Archer realiza de los términos acción y estructura no tiene como objetivo, en oposición al antidualismo, mostrar su dependencia absoluta, sino evidenciar la necesidad de comprenderlos como dos tipos de entidades diferentes, autónomas, pero interrelacionadas en un juego mutuo. La oposición vehemente de Archer a cualquier forma de teoría social que quiera volver prevalente a la parte estructural y objetiva (holismo) o que quiera reconocer simplemente la dimensión individual y subjetiva (individualismo) se justifica porque implica exagerar o eliminar la libertad individual y hacer caso omiso del carácter dual, al estilo de un rostro de Jano, de la naturaleza de la sociedad. De la misma manera, Archer considera que los antidualistas se equivocan porque, en lugar de ofrecernos un panorama claro sobre la libertad de los seres humanos en la sociedad y el poder determinante de las estructuras, nos proponen una dialéctica perniciosa y confusa que lleva a producir argumentos circulares y, si bien comprenden el carácter dual de la sociedad, representan a la cara de Jano como si ambas se verían mutua y sincrónicamente. Contra esta tesis, Archer propone que los dos rostros de Jano se ignoran mutuamente, en la medida en que miran a dos lados diferentes, pero que, necesariamente, son interdependientes sin perder su autonomía. El punto central de las propuestas dualistas consiste en observar por separado los poderes de la acción y de la estructura antes de observar su juego mutuo para no caer en vicios conceptuales.

Aun cuando Archer afirma la necesidad de remitirnos a acciones específicas para explicar una estructura, el reconocimiento de la necesidad interna de las relaciones que conforman la estructura es el factor que 
evita caer en el reduccionismo individualista que radica en considerar que estas no son más que el entrelazamiento de acciones individuales. Por ejemplo, el Estado, en oposición a la concepción de Weber, no depende de la posibilidad de acciones específicas, sino que existe por la objetividad de relaciones internas y necesarias entre distintos sujetos y entre sujetos y objetos, que implican roles y distribuciones desiguales de elementos materiales (el monopolio fiscal, de la violencia física, etc.), que surgen de acciones pasadas de actores específicos (actores muertos), pero que, debido a su carácter necesario e interno, se presentan como fenómenos emergentes con existencia real que condicionan y "limitan", mediante posiciones, roles e instituciones, a las acciones posteriores $\mathrm{y}$, por tanto, a todo fenómeno existente en el ámbito social. En palabras de Archer, "es necesario aceptar que los resultados de acciones pasadas [en la medida que crean fenómenos emergentes] tienen sus efectos independientemente en procesos posteriores, como influencias limitantes o habilitantes en los sujetos, y no pueden ser atribuidos o reducibles a las prácticas de otros agentes [en el tiempo]" (Archer, 1995: 90).

Por lo tanto, las estructuras se encuentran en un estrato emergente y tienen existencia propia e independiente de los individuos, pues las relaciones sociales que las conforman no son producto de acciones aisladas presentes ni totalmente voluntarias, sino que implican tanto su existencia objetiva como los poderes causales de la distribución desigual de recursos materiales que derivadas de las posiciones (poseer o no medios de producción), roles relacionados con aquellas posiciones (obrero capitalista) e instituciones específicas (fábricas) en tanto productos de acciones de personas muertos. En este sentido, para Archer las estructuras no son el resultado de acciones presentes, sino de acciones pasadas, cuyos efectos, al ser emergentes, influyen causalmente de forma independiente en procesos posteriores (Archer, 1995). En palabras de Archer, "son estructuras 
en virtud de ser propiedades emergentes que son irreductibles al hacer de los actores contemporáneos, puesto que derivan de acciones históricas que las generaron y, así, crean el contexto para la acción contemporánea" (Archer, 1995: 139). De esta forma, no se puede afirmar que la estructura sea actualizada en su confrontación con las acciones.

En este sentido, Archer considera que la estructura tiene distintos niveles estratificados: posiciones, roles e instituciones que se hallan interrelacionados (Archer, 1995). A nivel de instituciones, estas se hallan en relaciones de compatibilidad o incompatibilidad independientemente de la acción humana. Estas relaciones configuran los límites y habilitaciones de los roles que están involucrados en ellas. Por ejemplo, en una relación de compatibilidad entre Iglesia y Estado, tanto los sacerdotes como los gobernantes tienen marcos de acción distintos a los que tendrían si Iglesia y Estado tendrían una relación de incompatibilidad. De igual manera, los roles definen la distribución de recursos materiales a nivel posicional y dotan al agente de distintas posibilidades.

De aquí no se sigue que la socióloga británica afirme que la acción sea una variable dependiente de lo que sucede a nivel estructural, puesto que "las habilitaciones y limitaciones de las situaciones que confrontamos no son lo mismo que nuestros poderes de descripción o conceptualización [...] [y] la forma en que la realidad social ha devenido en ser lo que es no es un sinónimo con cómo nosotros pensamos que es" (Archer, 1995: 197). Así que, de acuerdo al dualismo, en oposición al individualismo, hay que evitar "confundir las capacidades de la mente humana con sus contenidos sociales" (Archer, 1995: 286): el ser humano tiene la capacidad de tener procesos mentales extrasociales y por tanto extralingüísticos, que derivan de un principio de humanidad que la autora inglesa otorga a los individuos.

En este sentido, las propuestas dualistas consideran que existe un fundamento humano común a partir del cual las personas actúan en 
sociedad y afrontan cualquier tipo de contexto cultural y estructural. Así, todo proceso de reflexión, planificación de la acción o articulación y formulación de metas son dependientes de propiedades más primitivas de las personas y no, como los antidualistas pretenden, de alguna propiedad estructural interiorizada. Esto sucede debido a que "se requiere de la agencia que sea reflexiva, intencional, promotora e innovadora" (Archer, 1995: 249). Este principio de humanidad solo puede ser definido de una manera realmente abstracta, dado que es, en principio, extrasocial. Archer lo define como la capacidad de autoconciencia y conciencia continua que permiten que el ser humano pueda reconocer su contextos estructurales, sus intereses y las consecuencias de sus acciones. Esto quiere decir que “es necesario reconocer que los humanos tenemos relaciones extrasociales con realidades extrasociales, que constituyen nuestra conciencia y lo que somos en cuanto a personas" (Archer, 1995: 290). Este primer estrato humano de la acción implica el reconocimiento y la capacidad de "aprender a diferenciar entre lo social de lo extrasocial" (Archer, 1995: 290) Archer reconoce esto cuando afirma que

cuando hablamos sobre lo que una persona puede hacer, estamos haciendo referencia al humano animal, dado que las capacidades características del homo sapiens (como una especie natural) no pueden ser atribuidas a la sociedad, aun cuando aquellas solo pueden ejercerse en esta. Por el contrario, los seres humanos deben tener una constitución física particular para poder ser influenciados socialmente (como aprender un lenguaje, aritmética o creación de herramientas). Aun en los caso donde lo biológico puede estar mediado por lo social en casi todos los aspectos o instancias, como el cuidado de los hijos, esto no significa que la mediación no es biológica ni que lo constitución física se vuelva un epifenómeno (Archer, 1995: 288). ${ }^{8}$

\footnotetext{
${ }^{8}$ Este punto da mucha ventaja al dualismo analítico frente a otras corrientes de la teoría social a la hora de producir trabajos interdisciplinares; pues considerar de esta forma al ser humano implica, en palabras de Archer, que "la sociobiología puede hacer aportaciones válidas sin superar su campo de estudio, siempre que los principios realistas de estratificación y emergencia sean respetados" (Archer, 1995: 288).
} 
Así, es necesario diferenciar entre los roles y poderes estructurales, $\mathrm{y}$ sus ocupantes que los personifican y ejercen sus efectos de formas características y singulares. Y, consecuentemente, es necesario diferenciar entre "el rol en sí mismo (que implica una definición anterior de las obligaciones, sanciones e intereses) y las cualidades personales que el actor lleva consigo - y desarrolla en juego mutuo con el rol-; aunque algunas de estas son eliminadas mediante un proceso activo de discriminación, que está estructuralmente condicionado pero que implica una selección del sujeto" (Archer, 1995: 187). Por esta razón, Archer habla de juego mutuo entre acción y estructura para entender la forma en que se dan los roles en la sociedad: la acción nunca es únicamente portadora (Träger) de la estructura.

A pesar de todas las propiedades emergentes de la estructura que afectan causalmente a la acción, los seres humanos son personas, es decir tienen capacidad de conciencia y de reflexión. Este modo de ser les otorga autonomía y poderes frente a las estructuras. Entre los poderes causales que se le atribuyen al individuo están la capacidad de aprehender el contexto, reflexionar sobre él y agruparse para articular intereses. De esta forma, las propuestas dualistas consideran que "el ser humano [en cuanto persona] es tanto ontológica como lógicamente anterior al ser social, cuyos poderes solo pueden emerger de los principios de humanidad" (Archer, 2000: 190). A partir de este "principio de humanidad", Archer postula que, en los humanos, se da la formación de agentes y actores en procesos que denomina "doble" y "triple" morfogenésis. Estos implican el cambio mediante el cual los individuos, al entrar en contacto uno con otro, se transforman a sí mismos, es decir, transforman sus intereses y las formas en que adoptan roles o valoran su posición (Archer, 1995).

La autonomía tanto de la acción y la estructura está asegurada en el marco teórico archeriano por dos factores importantes: el tiempo y la 
estratificación ontológica. La afirmación sobre la que se basa este postulado en el dualismo analítico de Archer es que el condicionamiento estructural necesariamente es anterior temporalmente a la acción y que cualquier efecto de esta es necesariamente posterior temporalmente a ella (Archer, 1995). La profesora de Warwick afirma que la temporalidad distinta de ambas entidades es una cuestión ontológica que

no solo permite reconocer su diferencia, sino también permite construir a las estructuras como preexistentes y constituyentes del ambiente de la acción contemporánea. Podemos ser más precisos sobre cómo esta mediación tiene lugar y caracterizarla como una influencia objetiva que condiciona los patrones de acción y provee a los agentes de guías estratégicas de acción (Archer, 1995: 196).

Sin embargo, el desfase temporal y la estratificación ontológica, producto de las propiedades extrasociales que se depositan en el ser humano, son la base de esta propuesta dualista. En este sentido, de manera general se puede afirmar que toda propuesta dualista debe negar la covariación a partir de considerar que existe un hiato inconciliable entre acción y estructura que se deriva de las propiedades extrasociales del humano y de las propiedades extrahumanas de la acción, pues solo así es posible hablar de "irritaciones" o "colonizaciones", tal como se lo hace en la propuesta dualista habermasiana o luhmanniana.

En consecuencia es necesario "analizar los mecanismos generativos potenciales que emanan de las estructuras (y cultura) como propiedades emergentes y su recepción por las personas, quienes poseen sus propiedades emergentes independientes de reflexión individual y social" (Archer, 1995: 175). Como observamos, Archer afirma que la capacidad reflexiva y la acción contingente deben ser tomadas en cuenta dado que "ningún condicionamiento socio-cultural ejerce influencia de forma hidráulica, puesto que está sometido a la evaluación reflexiva de agentes gracias a sus poderes de autoconciencia y autovigilancia” (Archer, 1995: 184). 
De esta forma, una de las premisas básicas del dualismo es reconocer que la realidad social es producto del juego mutuo de dos tipos de entidades -acciones y estructuras-, que poseen propiedades, poderes causales y efectos diferenciados, que de ninguna manera pueden covariar. De esta premisa se deriva que es necesario aceptar una realidad estratificada de lo social, en la que los distintos estratos -individuos (acciones) y sociedad (estructuras)- poseen propiedades que no covarían. Sin embargo, las implicaciones de este reconocimiento no se agotan en su afirmación como entidades diferentes y diferenciadas. Por el contrario, hay que advertir que ambas entidades poseen necesariamente su propio estrato en la medida en que pueden generar cambios drásticos en las causas potenciales de otros estratos. Archer soluciona este problema con la temporalidad, pero en otras propuestas dualistas se lo soluciona a partir de otras categorías teóricas como sistema/entorno o sistema/mundo de la vida. De aquí que los poderes causales, las propiedades y la existencia de los individuos y de las estructuras tienen una variación propia, pues esta constituye una condición necesaria para que acciones y estructuras adquieran total autonomía. Así, acción y estructura no son contemporáneas, sino extemporáneas, y de ninguna manera pueden covariar ni reflejarse nítidamente. Por ejemplo, los procesos de agrupación no son un reflejo de la distribución posicional de la estructura, así como tampoco la agrupación afecta inmediatamente a la forma en que se distribuyen los recursos, personas y oportunidades. La profesora de Warwick afirma que "cada entidad [estructuras y acciones] posee propiedades autónomas y emergentes que son, por tanto, capaces de una variación independiente, lo cual produce que puedan estar desfasadas en el tiempo" (Archer, 1995: 66).

De este modo, en el marco dualista no se afirma una simple unidad de análisis, sino que se muestra necesario estudiar cada uno de los niveles de la sociedad por separado para luego estudiarlos en su interrelación. Así pues, 
el dualismo analítico permite desarrollar estudios multiniveles en los que la explicación de cualquier fenómeno no se agota en una dimensión individual, supraindividual o en un proceso central como la práctica. El modelo morfogenético de Archer hace referencia precisamente a este proceso. En primer lugar, se afirma una etapa de condicionamiento causal en la cual se observan los resultados emergentes de las estructuras que condicionan la acción, es decir, las relaciones entre entidades supraindividuales que condicionan el contexto de la acción. En segundo lugar, un proceso de interacción sociocultural en el cual intervienen los poderes causales de los individuos que activan efectos causales potenciales de las estructuras de cambio o persistencia. Dentro de este proceso ocurre un transcurso que concierne efectivamente a las propiedades emergentes y causales de los individuos: la asimilación reflexiva de los condicionamientos estructurales, la relación entre sujetos que permite definir líneas de acción y la elaboración de grupos. Al mismo tiempo, se afirma que este proceso de agrupación o de interacción afecta causalmente la forma en que se da la agencia por medio de la morfogénesis de esta. Por último, se afirma la necesidad de estudiar la elaboración estructural de las acciones de los agentes, es decir, su influencia en las entidades supraindividuales.

De esta manera, dicho enfoque permite estudiar procesos de asimilación subjetiva de distintos condicionamientos estructurales autónomos (compatibilidad o contradicción entre entidades supraindividuales) al mismo tiempo que estimula el análisis de las consecuencias de las acciones reflexivas en el cambio o mantenimiento de lo social (morfogenésis o morfoestasis). Esta situación se debe a que, en el pensamiento de la profesora de Warwick, se considera que acción y estructura no presentan una dualidad sino un dualismo: dos conceptos que son distinguibles a nivel de pensamiento porque son distintos a nivel ontológico. Por tanto, la constitución de la realidad social depende 
de procesos de juego mutuo y de causalidades complejas en las que se reconocen las propiedades y poderes causales de acciones y estructuras autónomamente. En consecuencia, para toda propuesta dualista

\begin{abstract}
es necesario distinguir entre aquellas acciones que son ejercidas a partir de sus poderes intrínsecos y aquellas que, en realidad, son poderes que residen en las estructuras sociales, pero que operan a través de la actividad de los humanos [...] Hay que distinguir los poderes que los agentes poseen en virtud de su naturaleza intrínseca y los que poseen en virtud de sus propiedades relacionales (Archer, 1995: 197).
\end{abstract}

Esta tesis implica el reconocimiento de la causalidad emergente en la medida en que se acepta la posibilidad de establecer relaciones causales -(in)compatibilidad, contradicción, complementariedad- entre entidades supraindividuales; la causalidad submergente en la medida en que la situación estructural crea contextos de acción a nivel de roles y distribuciones; y, por último, causalidad superviniente en la medida en que se reconoce la dependencia de la actividad de las estructuras y la capacidad de las acciones de producir cambios en las estructuras (agencia).

En conclusión, toda propuesta dualista atribuye existencia autónoma a ambas entidades y la capacidad de desarrollarse de forma disímil, al mismo tiempo que se reconoce la mutua influencia entre ambas. Así, se reconoce una irreductibilidad relativa a ambas entidades: hay poderes causales propios de cada entidad que se ejercen por sí mismos en la medida que no covarían; pero se reconoce la capacidad de influirse mutuamente mediante algún tipo de mecanismo.

La relacionalidad que se deriva de estas premisas es contingente en la medida en que la forma en que los seres humanos afrontan las relaciones necesarias y los roles depositados en las estructuras dependen tanto de un principio de humanidad como de los procesos de agrupación e interacción de los individuos (doble y triple morfogénesis). En efecto, Archer afirma 
que de un proceso agencial a nivel de posiciones se pueden derivar formas novedosas de efectivizar los roles sociales existentes en las estructuras. Así que, si bien en la estructura se hallan depositadas relaciones a nivel de posiciones y roles que configuran la acción, la relación no se reduce a ellas, dado que la forma en que los individuos actúan está condicionada por elementos autónomos como el principio de humanidad y los procesos de interacción en la doble y triple morfogenésis.

Al poseer principios extrasociales, la mente humana es concebida en principio como algo que está más allá de las estructuras y que permite que las relaciones objetivas se efectivicen de formas contingentes mediante procesos de selección e interpretación complejos en los que interviene la interacción social y los procesos de agrupación. Por tanto, si bien la relacionalidad ocurre en espacios objetivos y estructuras determinadas, no se reduce a las potencialidades existentes sino que se construye a partir de este condicionamiento causal en relación con los poderes agenciales y la reconfiguración que estos ejercen sobre la relación misma. Este hecho implica que la relacionalidad ocurre a partir del juego mutuo no solo de estructuras y acciones, sino del que ocurre en las distintas dimensiones de la acción: evaluación práctica derivada de procesos agenciales y del principio de humanidad; iteración, en la medida en que la estructura condiciona los cursos de acción; y proyección, en cuanto de la interacción social pueden surgir guías de acción novedosas que no se encontraban en la estructura.

\section{Conclusión}

En primer lugar, tal como Piiroinen reconoce, uno de los puntos de discordia entre dualistas y antidualistas es la constitución de la mente humana (Piiroinen, 2014). Por un lado, los antidualistas consideran que esta es no solo socialmente limitada, sino que tiene su génesis en y por la 
sociedad. En este sentido, la racionalidad de una acción vendría dada por esquemas interiorizados de estructuras existentes. Mascareño diría que en estos casos "su autonomía queda subordinada a las definiciones de la acción, a los ejes de fuerza que se constituyan por vía del enfrentamiento fáctico [copresencia en contextos espacio-temporales (campos) específicos] de los actores y los resultados que de ello se deriven" (Mascareño, 2009: 74). Por el otro lado, los dualistas consideran que el individuo tiene mayores grados de autonomía en la ejecución de la acción y que pueden direccionarla con vistas a realizar cambios de forma racional y reflexiva o, como diría Piiroinen, tienen "una imagen de los agentes que son capaces de alterar su propio ser social en primer lugar en búsqueda de cambios - si no de sí mismos por lo menos en la estructura que los rodea y que va a cambiar contextos de interacción posteriores" (Piiroinen, 2014: 92).

En el primer caso, la mente humana queda reducida a lo que está contenido en la estructura social (relaciones objetivas, reglas, recursos, etc.); mientras que, en el segundo caso, la mente humana tiene propiedades anteriores a la estructura que moldean la forma en que se da el encuentro entre agencia y estructura. El esquema para enteder la configuración de la mente en los antidualistas sería: estructura social (ideal o material) -> relaciones sociales (posiciones en la estructura) -> interacción -> mente (intereses, reflexividad, racionalidad, motivaciones, esquemas de acción, etc); mientras que, para los antidualistas, sería mente primaria (propiedades intrínsecas del humano) -> relaciones sociales (posiciones en una estructura existente) e interacción -> mente (intereses, motivaciones y esquemas de acción).

La segunda conclusión que salta a la vista es que mientras los antidualistas abogan por una "complicidad ontológica" de la acción con la estructura, los dualistas consideran que entre ambos hay un "hiato ontológico". Por ende, los primeros conciben todas las acciones no como 
el producto de una planificación estratégica o reflexiva autónoma - en el sentido de proceder de una propiedad exclusivamente humana - sino como un "estar tomado por el juego", que resulta en un sentido práctico (doxa) entendido como estructura hecha cuerpo (habitus) o como rutina; y, a la sociedad, como el producto de estas acciones que (re)crean estructuras que los individuos interiorizan mediante la socialización. Por el contrario, los antidualistas reconocen a las estructuras una existencia anterior que posee causas no efectivas y consideran que la acción, por ser extemporánea y pertenecer a un estrato distinto en donde se activan poderes humanos $y$ extrasociales, solo puede considerarse como el producto de una conciencia reflexiva autónoma. De esta forma, la relacionalidad propuesta por ambas posturas gira en torno a que esta sea estructural en la medida en que reproduce elementos societales o que sea contingente en la medida que la dimensión humana (principios de humanidad) tiene un rol principal.

Para los antidualistas, los principios generadores de las experiencias subjetivas derivan de las estructuras y este hecho permite que las relaciones objetivas se efectivicen. Por el contrario, para los dualistas, los principios generadores de las experiencias subjetivas se producen en dos niveles: en primer lugar, se activa el principio de humanidad en su encuentro con la estructura humana en tanto sistema de posiciones (doble morfogenésis), de manera que se generan procesos de agrupación que luego configurarán, nuevamente en conjunto con el principio de humanidad, la forma en que los actores se involucran en un segundo nivel relacional de roles (triple morfogenésis). Por tal motivo, la relacionalidad para los dualistas nunca puede ser el resultado de lo que ocurre a nivel estructural.

La diferencia deriva de que en el antidualismo -en oposición al dualismo, que considera que ambas entidades deben ser tratadas como disímiles-, la idea de dualidad fusiona indisolublemente tanto la acción como la estructura en una unidad ontológica primaria; y así da paso a una 
forma de relacionalidad en la que esta es el producto de acciones en las que exclusivamente se activan propiedades estructurales. Tanto Giddens como Bourdieu consideran que la estructura de los holistas nos permite, como investigadores, romper la supuesta transparencia del mundo social al tomar en cuenta el rol de las estructuras, entendidas como contextos espaciotemporales de reglas, sentidos objetivos y relaciones sociales objetivas, en la configuración de los elementos integrantes de la acción: motivación, reflexividad, intereses, etc. Por otro lado, del individuo de los individualistas rescatan el papel que se otorga a la subjetividad humana y a la agencia en el proceso de construcción de lo social, pues, como diría Bourdieu, las estructuras sociales se presentan en la vivencia como objetos que no son pasivamente registrados sino construidos a partir de la subjetividad del agente que también está estructurada por la objetividad (Bourdieu, 2013a) o, como diría Giddens, los contextos son asimilados por el individuo, mediante la rutina, en la conciencia práctica y la conciencia discursiva. Sin embargo, esta asimilación o vivencia está determinada por las estructuras circundantes. Por esta razón, la formas en que las experiencias subjetivas se adaptan a las relaciones objetivas del sistema o del campo no son sino subproductos de propiedades estructurales o esquemas de pensamiento que se derivan de las estructuras.

Por el contrario, mientras que los antidualistas reducen acción y estructura a la práctica, los dualistas afirman su irreductibilidad. De aquí se sigue que en el antidualismo no es posible pensar un proceso unidireccional y sincronizado en el cual ambas entidades se coconstituyen y covarían en el tiempo, sino que su relación debe ser pensada a partir de la idea de un desfase que causa la extemporaneidad y la necesidad de inconcordancia entre ellas. La oposición de ambas posturas radica en que: mientras los antidualistas parten de un presupuesto de continuidad y covariación entre acción y estructura ("complicidad ontológica" y "dualidad de la estructura") 
y consideran que el desfase ocurre únicamente en casos extremos (histéresis del habitus y ruptura de la rutina), el dualismo toma axiomáticamente la inconcordancia y el desfase de ambas entidades y considera que la covariación es un fenómeno excepcional. De aquí se deriva una concepción de lo relacional totalmente opuesta, pues las experiencias subjetivas de las relaciones y las relaciones contenidas en las estructuras (a nivel de roles o posiciones) nunca son similares, puesto que se da lugar a procesos de agrupación y relacionamiento contingente en el que se involucra no solo el principio de humanidad sino los procesos de doble y triple morfogénesis. Así, al momento de activarse el principio de humanidad y crear formas contingentes de asociación y relación, estas formas, a su vez emergentes, configuran nuevas formas de relacionamiento.

En cuanto a la relacionalidad que se desprende de la propuesta antidualista, esta es, sin lugar a dudas, una relacionalidad estructural, pues, como afirma Donati, “considera lo relacional como el producto de las estructuras" (Donati, 2015: 3). En efecto, para Bourdieu y Giddens, las relaciones se configuran como un subproducto del sistema y del campo respectivamente a las cuales los individuos no dan nacimiento sino que reproducen mediante la acción recursiva del habitus o la dualidad de la estructura. De esta suerta, las relaciones quedan reguladas estructuralmente por propiedades extrahumanas en la medida en que no pertenecen al individuo. Aunque Donati critique esta postura porque observa las relaciones como producto de instancias no humanas (campo, estructura y sistema), es necesario reconocer que la sociedad y las dinámicas relacionales pueden operar -y, en efecto, operan- según estos principios recursivos estructurales en los que la mente humana está socialmente limitada. El problema de los antidualistas reside justamente en que consideran que este tipo de relación se deriva de una "complicidad ontológica" entre agencia y estructura, y no como una posibilidad histórica. 
Del mismo modo, pero en sentido inverso, la relacionalidad contingente es también el producto de situaciones históricas concretas en las que existen "imperativos reflexivos" que permiten un mayor espacio a la acción humana y su reflexividad propia. El problema de los dualistas reside en que consideran que las propiedades humanas se activan automáticamente en toda operación estructural para dar paso a una relacionalidad contingente y reflexiva. No es posible afirmar que en todas las relaciones existan procesos de reflexividad activa y continua $y$, por tanto, no todas las relaciones involucran los poderes causales de una mente humana autónoma.

En este sentido, existen intentos que, al modo de una réplica de lo que sucedía con el debate individualismo/holismo, buscan reconciliar el dualismo y antidualismo (Aedo, 2014; Decoteau, 2015; Elder-Vass, 2007). Una de las soluciones propuestas, consiste justamente en radicalizar la idea de histéresis del habitus de Bourdieu a la luz del dualismo archeriano, que insiste en la racionalidad, reflexividad y conciencia como propiedades indiscutibles del individuo, para pensar en la posibilidad de un "habitus reflexivo". En palabras de Decoteau,

pensar la histéresis significa poder analizar las fuerzas estructurales y culturales al menos analíticamente separadas de las experiencias subjetivos y prácticas [...] [Sin embargo] en el caso de la histéresis, el cambio no ocurre por la creatividad del agente, sino por la naturaleza dinámica del campo que el sujeto no puede controlar. La propuesta de un habitus reflexivo que integra la visión dualista supera las limitaciones en la teoría de Bourdieu" (Decoteau, 2015: 4).

Se podría argüir que esta radicalización de la histéresis no solo supera a la teoría de Bourdieu en su conceptualización de la estructura como dependiente de la actividad de sujetos presentes, sino también en cuanto a su concepción del individuo. El rechazo de Archer del término habitus se deriva del hecho de que la autora británica niega la idea de que lo social se 
incorpore en el sujeto (Archer, 2000; 2010). Por el contrario, pensar a la histéresis del habitus desde la perspectiva dualista implicaría dejar de ver al habitus como "estructuras interiorizadas" y pasar a concebirlo únicamente como "esquemas de acción" producto de la rutina que, al volverse caducos, generan un "imperativo reflexivo". Esta idea implica que, en oposición a Bourdieu, no se podría afirmar que el individuo sigue actuando a partir del habitus desfasado o que este se acopla a las estructuras (Bourdieu, 2013a), sino que el individuo adquiere grados de reflexividad que le permiten generar relaciones contingentes y dar nacimiento a proceso morfogenéticos.

Así, de ambas propuestas podemos rescatar que la estructura sea concebida en términos de un dispositivo limitacional de lo relacional, pero debemos rechazar que axiomáticamente se considere la mente humana como autónoma o limitada. Por el contrario, se debe apostar por la construcción relacional de la mente humana. Es decir, considerar momentos y configuraciones relacionales y estructurales que permiten que la mente posea más o menos reflexividad, que esté más o menos limitada socialmente. La intensificación del cambio social necesariamente se traduce en una generalización de la histéresis porque las experiencias pasadas no logran proveer de guías de acción eficientes para el presente y porque las expectativas subjetivas, inducidas estructuralmente, no encuentran realización en rendimientos objetivos estructurales

En tercer lugar, como se mencionó anteriormente, un punto en común entre posturas dualistas y antidualistas es que la estructura no se concibe como un determinante que ejerce presión hidráulica, sino como un dispositivo limítrofe de las operaciones que realiza el sujeto en su acción. Por esta razón, las ideas de habitus (Bourdieu), rutina (Giddens) y condicionamiento estructural (Archer) hacen referencia a la forma en que las estructuras habilitan y restringen ciertas prácticas. La diferencia radica justamente en cómo se concibe al ser humano y los poderes que se le 
asocian: los dualistas como un fenómeno autónomo de lo social, mientras que los antidualistas como un sujeto estrictamente social. Así pues, las operaciones del habitus deben ser consideradas creativas dentro de los límites de las estructuras y Bourdieu afirma así la necesidad de hablar de "libertad negativa". Por el contrario, Archer afirma que "las personas tienen cuerpos y los cuerpos humanos son cuerpos animales que tienen propiedades que constituyen la esencia real del homo sapiens" (Archer, 1995: 288) y de tal postura se deriva que este principio es el que genera la libertad y reflexividad humana y no la sociedad, como lo pretenden Bourdieu y Giddens.

Esta dependencia indisoluble de acción y estructura que concibe el antidualismo en la configuración de los componentes de la primera trae consigo ciertos riesgos estructuralistas; pues tanto el habitus como los tres niveles de conciencia reconocidos por Giddens muestran una acción sobresocializada o sobreestructurada en la medida en que mezclan indisolublemente la mente humana con los contenidos sociales. En palabras de Alexander,

el habitus no tiene un poder independiente para dirigir la acción, de la manera en que lo posee el "yo" (según Mead), la "personalidad" (en la perspectiva de Parsons). El habitus no nos conduce a una psicología social ni a problemas de identidad, carácter, adaptación e independencia. En vez de eso, a lo que da lugar es a una descripción interminable y circular de estructuras objetivas que estructuran a las estructuras subjetivas, que a su vez estructuran a las estructuras objetivas (Alexander, 2001: 55).

Evidentemente se podría criticar que las propiedades atribuidas por cualquier propuesta dualista al homo sapiens son, a pesar de su nivel de abstracción, arbitrarias y, por tanto, pueden generar reveses en su afán de resaltar la contingencia de la acción. De ahí que, en su intención de otorgar al individuo poderes independientes para dirigir la acción, las propuestas 
dualistas llevan en sí la marca del esencialismo en tanto se considera que existen propiedades inherentes a la mente humana que fundamentan el desarrollo la acción.

En cuarto lugar, es importante recalcar que la teoría de Archer se construye desde la crítica al antidualismo, bajo la etiqueta de elisionismo, cuyos defectos, según la profesora de Warwick, consisten en fusionar y volver indistinguibles acción y estructura en la práctica. Los contraargumentos tardaron pero no podía creerse que el dualismo iba a aplastar la voluntad de sus adversarios de defenderse. En este sentido, Piirinoinen defiende al antidualismo, pues considera que el individuo humano no puede ser pensado nunca como un ser autónomo de lo social, tal como Archer afirma que sucede cuando diferencia entre personas, agentes y actores (Piiroinen, 2014). La crítica se dirige al dualismo en la medida en que no puede explicar, según Piiroinen, procesos identitarios que no requieren de evaluación y aceptación reflexiva del agente, sino de "cargas de emociones primarias relacionadas imágenes e iconos en conjunto con personas idolatradas, que son intrínsecamente sociales" (Piiroinen, 2014: 93). Lo que Piiroinen argumenta es, siguiendo a los antidualistas, que no se puede pensar a la reflexividad como un fenómeno separado de la dinámica social que se activa en todo momento en que acción y estructura se encuentran, sino como el producto de oportunidades estructurales -ruptura de rutina o histéresis del habitus- y condicionamientos estructurales (illusio) que permiten la acción reflexiva y no una acción rutinaria producto del (des)conocimiento del mundo objetivo traducido en el habitus o en la rutinización de la acción.

Esta oposición entre las soluciones dualistas (Archer) y antidualistas (Bourdieu y Giddens) ha hecho que algunos consideren que el debate acción/estructura superó la confrontación holismo/individualismo y se pasó a considerar que el rumbo del debate está entre emergentistas (dualistas) y 
elisionistas (antidualistas) (Archer, 1995; Piiroinen, 2014; Prandini, 2015). No se desconoce que existan otras propuestas de superación del debate, pero se reconoce que estas pueden analizarse desde la distinción dualistas/ antidualistas, cuyas máximas se han expuesto en este artículo. Una de ellas es la de Habermas; quien, a partir de la distinción entre mundo de la vida y sistema, propone una visión dualista en la que se considera que los procesos de integración sistémica ocurren a un nivel específico, mientras que los de integración social a otro y que dependen de principios distintos y contrapuestos (autorregulación funcional y acción comunicativa, o razón instrumental y razón comunicativa) (Habermas, 2001); y, al mismo tiempo, que existen fenómenos de influencia mutua a partir de conceptos como el de colonización del mundo de la vida. En la propuesta habermasiana, sin embargo, se encuentran ambivalencias en las que se puede observar una postura en la que se da más autonomía al nivel de la acción y otra en la que parece ser que se le da primacia a la estructura (Mascareño, 2008). ${ }^{9} \mathrm{De}$ igual forma, se podría argüir que la sociología ha desarrollado grados de sofisticación elevados que impiden que muchas teorías se clasifiquen dentro de estos parámetros. Sin embargo, consideramos que el debate acción/ estructura ya no debe pensarse exclusivamente en términos de holismo/ individualismo sino también en el marco de la antinomia antidualismo/ dualismo para mejorar la comprensión de la teoría sociológica hoy.

Por tanto, si bien Bourdieu y Giddens consideran que el falso dualismo de acción y estructura se evidencia en la práctica, no se puede afirmar que todas las propuestas antidualistas utilicen este dispositivo teórico específico para demostrar la inseparabilidad de ambas dimensiones.

\footnotetext{
${ }^{9}$ Esto ocurre, según Mascareño (2008), por la concepción ambivalente del Derecho. En un primer momento, representado por La teoría general de la acción comunicativa, este se concibe como vehículo de colonización del mundo de la vida; mientras que, en un segundo momento, representado en Facticidad y Validez, como proceso que permite, mediante la deliberación en parlamentos, la influencia de lo que ocurre en el mundo de la vida en el sistema.
} 
De igual manera, el desfase temporal y la emergencia son los dispositivos teóricos que la propuesta dualista de Archer utiliza para mostrar la autonomía de los individuos y las estructuras, pero de ninguna manera se podría afirmar que todas las propuestas dualistas utilizan estos mismos dispositivos para garantizar dicha independencia.

Aislar esta idea nos permite tener claro cómo debería ser un marco metateórico dualista y uno antidualista. Cualquier marco de referencia que considere la relación entre acción y estructura como un falso dualismo que debe ser superado y utilice en su arquitectura teórica un concepto equivalente al de práctica, que muestra la inseparabilidad de acción y estructura, así como la posibilidad única de ejercer sus poderes causales cuando se relacionan entre ellos, entra en la categoría antidualista. Además, toda arquitectura teórica dualista debe suponer, a nivel de fundamento operativo, alguna noción homóloga a la noción de habitus o rutina, mediante la cual los individuos interiorizan las estructuras sociales provocando que su mente solo pueda ser pensada como mente social; es decir que no solo la lógica con la que actúan los agentes sea una lógica social en la medida que sirve para actuar en sociedad sino que también la racionalidad y los intereses no pueden sino tener un origen y fundamento social. Al mismo tiempo implica adoptar categorías (como dualidad o campo) que permitan pensar las estructuras como producto únicamente humano.

Por el contrario, toda teoría que piensa acción y estructura como fenómenos autónomos pero interrelacionados y tiene dispositivos teóricos equivalentes a la emergencia y al desfase temporal archerianos, que reemplazan y cumplen la función de otorgar autonomía y reconocer poderes causales propios y irreductibles a la acción y a la estructura, entran en el dualismo. Por su parte, a nivel de fundamento operativo, toda propuesta dualista debe, sin lugar a dudas, a nivel de fundamento operativo, otorgar contenidos extrasociales a la mente humana, es decir, considerar que 
existe una lógica y racionalidad unitaria que se desprenden de un principio de humanidad anterior al ámbito de lo social. Al mismo tiempo, debe poseer dispositivos teóricos que otorguen contenidos extrahumanos a las estructuras sociales.

Por último, como se ha argumentado, debido a principios ontológicos ligados a la constitución de la mente humana, y los poderes humanos y estructurales, toda propuesta que posea características dualistas nos remitirá a una relacionalidad contingente en la medida en que las relaciones, a pesar de estar contenidas potencialmente en las estructuras, siempre dependerán de factores extrasociales que son considerados principios humanos (como el principio de conciencia en Archer o la acción comunicativa en Habermas). Por el contrario, las propuestas dualistas no remiten a una relacionalidad estructural en la medida en que las relaciones y la experiencia subjetiva de ellas son conceptualizadas como un subproducto del sistema y un campo expresado en habitus o dualidad de la estructura.

\section{Referencias}

Alexander, J. (2001). La subjetivación de la fuerza objetiva. Iztapalapa, 50, 53-72. Archer, M. (1982). Morphogenesis versus structuration: on combining structure and action. The British Journal of Sociology, 33(4), 455-483.

Archer, M. (1995). Realist Social Theory: The Morphogenetic Approach. Cambridge: Press Syndicate of the University of Cambridge.

Archer, M. (2000). Being Human. The problem of agency. Cambridge: Cambridge University Press.

Archer, M. (2010). Routine, Reflexivity and Realism. Sociological Theory, 28(3), 272-303.

Bendix, R. (1971). Two Sociological Traditions (282-298). En G. Roth, \& R. Bendix, Scholarship and Partisanship: Essays on Max Weber. Los Angeles: University of California Press. 
Bourdieu, P. (1981). Men and machines (304-317). En K. Knorr-Cetina, \& A. Cicourel, Advances in Social Theory and Methodology: Toward and Integration of Micro- and Macro-Sociologies. Londres: Routledge.

Bourdieu, P. (1985). The genesis of the concept habitus and field. Sociocriticism(2), 11-24.

Bourdieu, P. (2008). Invitación a la sociología reflexiva. Buenos Aires: Siglo XXI Editores.

Bourdieu, P. (2013a). El sentido práctico. Buenos Aires: Siglo XXI Editores.

Bourdieu, P. (2013b). La nobleza del Estado. Buenos Aires: Siglo XXI Editores.

Decoteau, C. (2015). The reflexive habitus: Critical realist and Bourdieusian social action. European Journal of Social Theory, 1-19.

Dépelteau, F. (2013). What is the direction of the "relational turn"? (163-185). En C. Powell, \& F. Dépelteau (Eds), Conceptualizing Relational Sociology. Ontological and Theoretical Issue. New York: Palgrave Macmillan.

Donati, P. (2015). Manifesto for a Critical Realist Relational Sociology. International Review of Sociology: Revue Internationale de Sociologie. DOI: 10.1080/03906701.2014.997967

Durkheim, E. (2009). Las reglas del método sociológico y otros escritos. Madrid: Alianza Editorial.

Emirbayer, M., \& Mische, A. (1998). What is agency?. American Journal of Sociology, 103(4), 962-1023.

Giddens, A. (1979). Central problems in social theory: action, structure and contradiction in social analysis. Berkeley: University of California Press.

Giddens, A. (1995). La Constitución de la Sociedad: bases para la teoría de la estructuración. Buenos Airea: Amorrortu Editores S.A.

Gil Villegas, F. (2014). Introducción a Economía y Sociedad (9-109). En M. Weber, \& F. Gil (Ed.), Economía y Sociedad. México D.F.: Fondo de Cultura Económica.

Habermas, J. (2001). Teoría de la acción comunicativa, II. México D.F.: Taurus.

Kemp, S. (2012). Interests and Structure in Dualist Social Theory: A Critical Appraisal of Archer's Theoretical and Empirical Arguments. Philosophy of 
the Social Sciences, 42(4), 489-510.

Marx, K. (1977). El capital. Buenos Aires: Siglo XXI Editores.

Marx, K. (2012). Prólogo de la contribución a la crítica de la economía política (173-180). En K. Marx, Escritos de materialismo histórico. Madrid: Alianza Editorial.

Mascareño, A. (2008). Acción, estructura y emergencia en la teoría sociológica. Revista de sociología de la Facultad de Ciencias Sociales-Universidad de Chile(22), 217-256.

Mascareño, A. (2009). Acción y estructura en América Latina. De la matriz sociopolítica a la diferenciación funcional. Persona y sociedad, XXIII(2), 65-89.

Mommsen, W. (1965). Max Weber's political sociology and his philosophy of world history. International Social Science Journal, XVII, 23-45.

Parsons, T. (1979). On theory and metatheory. Humboldt Journal of Social Relations, 7(1), 5-16.

Piiroinen, T. (2014). For "Central Conflation": A critique of archerian dualism. Sociological Theory, 32(2), 79-99.

Prandini, R. (2015). Relational sociology: a well defined sociological paradigm or a challenging 'relational turn' in sociology? International Review of Sociology, 25(1), 1-14.

Ritzer, G. (1993). Teoría sociológica contemporánea. Madrid: McGraw-Hill.

Ritzer, G., \& Gindoff, P. (1992). Methodological Relationism: Lessons for and from Social Psychology. Social Psychology Quarterly, 55(2), 128-140.

Weber, M. (2006). Sobre algunas categorías de la sociología comprensiva (175222). En Ensayos sobre metodología sociológica. Madrid: Amorrortu Editores.

Weber, M. (2014). Economía y Sociedad. México D.F.: Fondo de Cultura Económica. 